\title{
LÓGICA Y PREMISAS IMPLÍCITAS EN LAS CONTRADICCIONES DE TESIS*
}

\author{
José Ramón Cossío Díaz***
}

RESUMEN. En su calidad de Ministro de la Suprema Corte mexicana, en el siguiente voto particular el autor defiende la existencia de una contradicción de criterios (de tesis) entre dos órganos jurisdiccionales del Poder Judicial de México incluso cuando no estén expresamente señalados en el fallo; considera que es condición suficiente que los criterios se encuentren implícitos en la argumentación. Para sostener su afirmación, el autor explica el papel de la lógica en la aplicación del derecho, establece una serie de reglas metodológicas que considera se deben tomar en cuenta para identificar un criterio implícito -entimemático-, y recomienda algunos pasos a seguir tanto en el aspecto formal como en el material de la argumentación para resolver cualquier tipo de contradicción de tesis.

Palabras clave: contradicción de tesis, lógica, criterios implícitos.

ABSTRACT. In his dissenting opinion, the author, as a Justice in the Mexican Supreme Court, maintains the existence of a contradiction of criteria (of thesis) between two national courts in the Mexican judiciary, even when they are not specifically mentioned in the ruling. He considers that it is a sufficient condition that the criteria are implicit in the reasoning. To support his assertion, the author explains the role of logic in the application of law, establishes a series of methodological rules, which he considers should be taken into account in order to identify an implicit criterion -entimematic-, and recommends certain steps to be taken, in both the formal and the material aspect of reasoning, in order to solve any kind of contradiction of theses.

Keywords: Contradiction of theses, logic, implicit criteria.

* El contenido de este documento derivó del voto particular que formuló el Ministro José Ramón Cossío Díaz, al que se adhieren los Ministros Genaro David Góngora Pimentel, José de Jesús Gudiño Pelayo y Guillermo I. Ortiz Mayagoitia, en relación con la contradicción de tesis 2/2006-PL, sustentada entre la Primera y la Segunda Salas de la Suprema Corte de Justicia de la Nación.

** Se agradece el apoyo del Doctor Roberto Lara Chagoyán para la elaboración de este documento. 
a Suprema Corte de Justicia de la Nación de México es el único tribunal que puede resolver las posibles contradicciones que se presenten entre criterios (tesis) emitidos por tribunales federales. Si las contradicciones son penales o civiles, las resuelve la Primera Sala de la Corte, y si son administrativas o laborales, la Segunda Sala. Cada Sala se integra por 5 ministros (magistrados). Puede también darse el caso de que entre la Primera y la Segunda salas existan criterios que se denuncien como contradictorios y el Tribunal Pleno de la Corte, formado por los integrantes de las dos salas más el presidente, es quien resuelve la contradicción. En toda contradicción de criterios se determina, en primer lugar, si existe la contradicción y, en segundo, qué criterio debe prevalecer. Así, muchas denuncias de contradicción no llegan al segundo paso, porque la Sala o el Pleno, según se trate, determinan que la contradicción es inexistente.

El presente voto particular deriva de una resolución emitida por el Tribunal Pleno de la Suprema Corte de Justicia de la Nación de México (CT-2/2006-PL). El planteamiento que se resolvió fue si entre dos criterios sustentados por cada una de las dos salas de la Corte existía o no contradicción y qué criterio debía prevalecer. Se analizó un fallo de la Primera Sala (CT-99/2005-PS) contra tres fallos de la Segunda (CT127/2001-SS, CT-33/94 y CT-38/93). Estos fallos derivaban, a su vez, de contradicciones que resolvió cada una de las salas de la Corte.

El tema a dilucidar se constriñó a determinar si existe una contradicción cuando al menos uno de los criterios contendientes es implícito o si, por el contrario, es necesario que tales criterios sean expresos. La mayoría de los ministros estuvieron de acuerdo en que la Segunda Sala admite la primera posibilidad, mientras que la Primera Sala asume la segunda de las posturas. En consecuencia, concluyeron que la contradicción era existente y que debía prevalecer el criterio de la Segunda Sala.

Diferí de la mayoría de los ministros en cuanto a la existencia de la contradicción. Para mí, puede perfectamente existir una contradicción a partir de criterios implícitos, pero en los fallos sometidos a análisis no existía realmente una genuina contradicción. Así, en el voto, expreso las razones por las cuales considero que no existe la contradicción (1); hago referencia al papel de la lógica en la aplicación del Derecho (2); expongo una serie de reglas metodológicas que considero se deben tomar en cuenta para identificar un criterio implícito (3); y finalmente, digo cuáles son los pasos que conviene seguir, tanto en el aspecto formal como material, a la hora de resolver cualquier tipo de contradicción de criterios (4).

$$
* * *
$$

El día doce de junio de dos mil seis, este Tribunal Pleno de la Suprema Corte de Justicia de la Nación abordó el estudio de la contradicción de tesis 2/2006-PL, sustentada entre la Primera y la Segunda Salas de la Suprema Corte de Justicia de la Nación. En ella, la mayoría de los ministros integrantes del Tribunal Pleno determinaron declarar existente la contradicción de tesis entre los criterios sustentados por la Primera y la Segunda Salas de la Suprema Corte de Justicia de la Nación, al resolver, respectivamente, las contradicciones de tesis que a continuación se enuncian: 
Primera Sala: CT-99/2005-PS ${ }^{1}$

Segunda Sala: CT-127/2001-SS 2 , CT-33/94³ y CT-38/93 4.

El tema a dilucidar se constriñó a determinar si se puede integrar una contradicción de tesis cuando al menos uno de los criterios contendientes es implícito o si, por el contrario, es necesario que tales criterios sean expresos. La mayoría de los ministros estuvieron de acuerdo en que la Segunda Sala admite la primera posibilidad, mientras que la Primera Sala asume la segunda de las posturas. En consecuencia, concluyeron que la contradicción de tesis existe y que debe prevalecer el criterio del Tribunal Pleno que es esencialmente idéntico al de la Segunda Sala.

Los motivos que me llevan a la formulación del presente voto particular serán expuestos en cuatro partes: 1) en primer lugar, me referiré a que, desde mi punto de vista, no existe contradicción de tesis entre las salas de este alto tribunal a partir de los casos sometidos a su consideración; 2) en segundo, hablaré sobre el papel de la lógica en la aplicación del Derecho; 3 ) por otro lado, estableceré una serie de reglas metodológicas que considero se deben tomar en cuenta para identificar un criterio implícito, y 4) finalmente, me referiré a los pasos que conviene seguir, tanto en el aspecto formal como material, a la hora de resolver cualquier tipo de contradicción de tesis.

\section{SOBRE LA NO EXISTENCIA DE LA CONTRADICCIÓN DE TESIS}

1.1. En primer lugar, quiero expresar que los ministros que integramos la Primera Sala nunca hemos estado en contra de que existan contradicciones de tesis que contengan criterios implícitos. Por ejemplo, la contradicción de tesis n. ${ }^{\circ}$ 105/2005-PS, entre las sustentadas por los Tribunales Colegiados Primero y Segundo, ambos en materia penal del primer circuito, resuelta bajo mi ponencia, en sesión de fecha veintiocho de septiembre de dos mil cinco 5 .

En ella, uno de los criterios contendientes era implícito, tal como se puede apreciar en la siguiente transcripción (se añaden énfasis):

«Así, el Primer Tribunal Colegiado en Materia Penal del Primer Circuito, al resolver el juicio de amparo directo penal 2917/1999, implícitamente adopta el criterio de que se configura el delito violencia en contra de los miembros de una guardia, previsto y sancionado en los arts. 278 y 279, fracción II, del Código de Justicia Militar, aun cuando el sujeto activo se encuentre franco el día que acontecieron los hechos; en esta tesitura, se surte competencia a favor del Supremo Tribunal Militar para que conozca este asunto» ${ }^{6}$.

${ }^{1}$ Bajo la ponencia del Ministro José Ramón Cossío Díaz.

2 Bajo la ponencia del Ministro José Vicente Aguinaco Alemán.

3 Bajo la ponencia del Ministro Humberto Román Palacios.

${ }^{4}$ Bajo la ponencia del Ministro Sergio Salvador Aguirre Anguiano.

5 El tema a dilucidar era si los delitos previstos en el libro Segundo del Código de Justicia Militar requieren para su acreditación que el militar que los cometa lo haga con motivo del servicio que desempeña o si, por el contrario, la calidad de militar en activo es suficiente para determinar la existencia de dichos delitos.

${ }^{6}$ P. 25, tercer párrafo, de la Contradicción de Tesis n. ${ }^{\circ} 105 / 2005$-PS, entre las sustentadas por los Tribunales Colegiados Primero y Segundo, ambos en materia penal del primer circuito. 28 de septiembre de 2005. Cuatro votos. Ausente: Ministro Juan N. Silva Meza. 
En contraste, no existe ningún asunto en el que la Primera Sala haya negado la posibilidad de la existencia de contradicciones de tesis en las que alguno de los criterios sea implícito. Ni siquiera el criterio que se sometió a la consideración de los señores ministros integrantes del Tribunal Pleno en el presente asunto - la contradicción de tesis identificada con el número de expediente CT-99/2005-PS—, tal como lo demostraré a continuación.

1.2. En segundo lugar, y una vez aclarado lo anterior, conviene traer a colación cada uno de los asuntos que se plantearon como contradictorios:

Por parte de la Segunda Sala, los criterios que se oponen al criterio de la Primera, se derivan de las contradicciones de tesis CT-127/2001-SS; CT-33/94 y CT-38/93.

En el primer asunto (CT-127/2001-SS), la Segunda Sala determinó que la contradicción planteada era inexistente. Parece por lo menos contraintuitivo que tal asunto se hubiera considerado como oponible en el presente caso, ya que lo que se buscaba determinar era si es posible que se actualice una contradicción —existente, claro estáen la que al menos uno de los criterios fuera implícito. En otras palabras, en este asunto se determinó que no existía contradicción de tesis ni siquiera de manera implícita - ésta es la única referencia a lo implícito que se encuentra en esa ejecutoria-, con lo cual no se cuenta con un elemento de contraste con relación a la contradicción entre Salas a que este voto se refiere. Lo anterior, porque se trata del «no empleo de criterios implícitos», esto es, de un hecho negativo.

En el segundo (CT-33/94), la Segunda Sala admite la posibilidad de que la contradicción de tesis se suscite aun cuando en uno de los criterios se haya hecho un "pronunciamiento indirecto":

«Cabe aclarar, que el hecho de que uno de los criterios materia de la contradicción de tesis denunciada haya hecho pronunciamiento indirecto sobre la aceptación de la procedencia de la ampliación de la demanda, según los términos de las disposiciones de la Ley Federal de los Trabajadores al Servicio del Estado, no impide que pueda analizarse la contradicción planteada, pues si de dicho criterio se infiere que es contrario al que plantea el órgano colegiado contendiente, ello basta para estimar que se satisfacen los requisitos que se exigen para la existencia de la contradicción, en virtud de que tal discrepancia tiene jurídicamente los mismos efectos que un desacuerdo expreso» ${ }^{7}$.

Finalmente, en el tercero de los casos (CT-38/93), el razonamiento de la Segunda Sala de la Suprema Corte de Justicia de la Nación queda contenido en el siguiente texto que, en aras de la claridad, conviene transcribir (se añaden énfasis):

${ }^{7}$ A partir de este asunto, se generó la tesis aislada que se utiliza en el caso como representativa del criterio de la Segunda Sala. Se trata de Tesis n. ${ }^{\circ} 2 .^{a}$ LXXVIII/95 de la Novena Época, emitida por la Segunda Sala, consultable en la p. 372 del tomo II, correspondiente al mes de septiembre de 1995, del Semanario Judicial de la Federación y su Gaceta. El rubro y el texto rezan: «CONTRADICCIÓN DE TESIS. PROCEDE SU ANÁLISIS AUNQUE UNO DE LOS CRITERIOS DIVERGENTES SEA IMPLÍCITO, SIEMPRE Y CUANDO EL SENTIDO DE ÉSTE PUEDA DEDUCIRSE INDUBITABLEMENTE. El hecho de que uno de los criterios divergentes materia de la contradicción de tesis denunciada, sea implícito, no impide que pueda analizarse y resolverse la contradicción planteada, pero para que la divergencia tenga jurídicamente los mismos efectos que un desacuerdo expreso al resolver cuestiones esencialmente iguales, se requiere que el sentido atribuido al criterio tácito sea indubitable». Contradicción de tesis 33/94. Entre los Tribunales Colegiados Primero y Noveno en Materia de Trabajo del Primer Circuito. 23 de junio de 1995. Cinco votos. Ponente: Genaro David Góngora Pimentel. Secretaria: Rosalba Becerril Velázquez. 
«Sobre el particular el Segundo Tribunal Colegiado del Cuarto Circuito sostiene que la regla establecida en el párrafo primero del art. 248 del Código Fiscal de la Federación, en lo relativo a la cuantía del asunto, no le es aplicable a la Secretaría de Hacienda y Crédito Público porque en relación con esa autoridad rige la regla contenida en el párrafo cuarto de ese precepto, conforme al cual la Secretaría mencionada podrá interponer el recurso cuando la resolución o sentencia afecte el interés fiscal de la Federación y, a su juicio, el asunto tenga importancia independientemente de su monto.

Por su parte, el Tercer Tribunal Colegiado del Cuarto Circuito si bien no expuso consideraciones expresas en cuanto a la aplicación del párrafo primero del mencionado art. 248, al aceptar que el recurso de revisión interpuesto por la Secretaría de Hacienda y Crédito Público es procedente con la sola invocación [por] parte de la recurrente de la cuantía del asunto, tácitamente sostiene que si le es aplicable a esa autoridad el primer párrafo del aludido precepto».

En este asunto, la Segunda Sala determinó que cada uno de los tribunales contendientes arribaron a conclusiones distintas sobre el mismo problema, habiéndose desprendido, de manera implícita, la posición de uno de los tribunales.

Por su parte, el criterio de la Primera Sala que se opuso a los anteriores es el identificado con el número de expediente CT-99/2005-PS. En él se resolvió esencialmente que no existía contradicción de tesis entre los criterios contrapuestos, porque uno de los tribunales ${ }^{8}$ afirmó que no es necesaria la ratificación de la autorización ante el juzgado para que los abogados procuradores puedan articular posiciones, habiendo dado, para ello, una serie de razonamientos en los que fundó su dicho, mientras que el otro Tribunal Colegiado ${ }^{9}$ señaló aparentemente lo contrario, pero sin haber motivado su afirmación, es decir, sin justificar con razones esa aseveración. En consecuencia, se resolvió que, ante la imposibilidad de realizar un contraste de criterios, por un lado, debido a la falta de uno de los razonamientos y, por otro lado, debido a la ambigüedad de una de las afirmaciones, la contradicción era inexistente.

1.3. Una vez que se ha aclarado lo anterior, considero necesario señalar que para resolver el presente asunto se debió partir de la siguiente cuestión: ¿puede considerarse con propiedad que en la contradicción de tesis de la Primera Sala, identificada con el número de expediente CT-99/2005-PS, se niega la posibilidad de la existencia de la contradicción basada en criterios implícitos? De la respuesta a esta interrogante depende, a mi juicio, la existencia de la presente contradicción de tesis.

Para estar en condiciones de determinar lo anterior, conviene traer a colación la ratio decidendi de ese asunto. Como se dijo, en esa ejecutoria se resolvió que no existía contradicción de tesis entre los criterios contrapuestos, porque uno de los tribunales afirmó que no era necesaria la ratificación de la autorización ante el juzgado para que los abogados procuradores pudieran articular posiciones, habiendo dado, para ello, una serie de razonamientos en los que fundó su dicho; por su parte, el otro Tribunal Colegiado expresó de manera ambigua una frase a partir de la cual - consideró la Primera Sala - no era posible llevar a cabo un verdadero contraste con respecto al primer criterio; además de no haber apoyado con razones tal aseveración.

\footnotetext{
8 Segundo Tribunal Colegiado del Decimoquinto Circuito. Amparo en revisión 71/2005.

9 Tercer Tribunal Colegiado del Decimoquinto Circuito. Amparo en revisión 698/2002.
} 
La frase de la que se deriva esa contradicción es, como se dijo, problemática, porque deja ver una ambigüedad: que la ratificación es necesaria y que no lo es, ya que se dice textualmente (se añaden énfasis):

«...si bien conforme a las disposiciones normativas en consulta el mandato que se confirió a sus abogados requiere que se ratifique ante la presencia judicial, también lo es que dicha determinación no le depara un perjuicio de imposible reparación $[. ..] \gg$.

En ese caso los ministros de la Primera Sala consideramos que esa frase ambigua — que además no estaba relacionada con la litis de la ejecutoria - no podía constituir un criterio contradictorio con respecto al que se le opuso, esencialmente, porque no existía materia para realizar el contraste, esto es, no había un argumento que contrastar con el otro.

1.4. En ese orden de ideas, y ya refiriéndome en concreto a la presente contradicción de criterios entre los sustentados por las salas Primera y Segunda de esta Suprema Corte de Justicia de la Nación, considero que el asunto al que acabo de referirme (CT-99/2005-PS) no constituye un ejemplo genuino en el que se niegue la posibilidad de la existencia de contradicciones de tesis tomando en cuenta al menos un criterio implícito.

El problema que resolvió la Primera Sala, a mi juicio, no tiene nada que ver con la existencia o no de criterios implícitos sino con la imposibilidad material de hacer un contraste. Esa situación, por lo demás, no está a discusión y más bien ha sido aceptada por este Tribunal Pleno.

Todos coincidimos en que, para que exista contradicción entre criterios, no basta que uno de los tribunales afirme lo que el otro niega, sino que es menester que existan argumentos jurídicos que sustenten las afirmaciones que se suponen en contradicción.

El problema no es entonces de premisas implícitas o no premisas implícitas, se trata más bien de la ausencia de argumentos. Me parece que es claramente diferenciable un problema de premisas implícitas de un problema de ausencia o presencia de argumentos.

La tesis de la Segunda Sala que se utiliza para resolver contradicciones en las que al menos uno de los criterios es implícito dice con toda claridad que el hecho de que uno de los criterios divergentes sea implícito, no impide que pueda analizarse y resolverse la contradicción planteada, pero se requiere - dice con precisión- «que el sentido atribuido al criterio tácito sea indubitable» ${ }^{10}$. ¿Cómo va a deducirse algo indubitablemente si no hay un argumento construido? ¿A partir de una ausencia de argumentación vamos a inferir más allá de una posibilidad lógica, mediante la construcción de las premisas?

Si se responde afirmativamente esa última cuestión, no sólo se estaría construyendo una parte del argumento (una premisa) sino la totalidad del argumento, y sobre ello se estaría construyendo de manera artificiosa la contradicción.

Podría discutirse si para que exista la contradicción basta la oposición formal (en términos estrictamente lógicos $\mathrm{A}$ es $\mathrm{B} v$ s. A no es $\mathrm{B}$, sin atender al contenido) o si, en

\footnotetext{
${ }^{10}$ Ut supra, nota 4.
} 
cambio, es necesario oponer los criterios materiales atendiendo al contenido. Pero esto no tiene que ver con el tema de lo implícito.

En conclusión, considero que en el presente caso el criterio de la Primera Sala, derivado del expediente CT-99/2005-PS, no reúne las características necesarias para que pueda ser considerado como un ejemplo representativo de contradicción de tesis en la que al menos uno de los criterios contendientes sea implícito. Para determinar cuáles son esas condiciones, es necesario elaborar una suerte de criterio que permita guiarnos, desde el punto de vista metodológico, a la hora de identificar criterios implícitos. Siempre he considerado conveniente que sea el propio Tribunal Constitucional el que construya o diseñe este tipo de guías metodológicas de forma más o menos abstracta para poder emplearse consistentemente en casos análogos.

\section{SOBRE EL PAPEL DE LA LÓGICA EN LA APLICACIÓN DEL DERECHO.}

Considerar que en las sentencias se expresen razonamientos lógicos no significa que se reduzcan a la construcción de tres premisas: mayor, menor y conclusión, bajo las conocidas figuras y modos del silogismo: BARBARA, CELARENT, DARII, FERIO, etcétera. Esto se ha convertido ya en un lugar común. Lo que hoy en día priva, y esta Suprema Corte ha hecho un extraordinario esfuerzo en ese sentido, es la construcción de razonamientos por vía de argumentación jurídica, y no por la aplicación simple y llana de silogismos.

Si estamos utilizando la argumentación jurídica, preguntémonos qué característica tiene ésta, y la respuesta es: la argumentación jurídica es un conjunto de criterios lógicos que son necesarios pero no suficientes para la construcción del razonamiento judicial. La argumentación jurídica emplea, además del razonamiento lógico, otro tipo de razonamientos como son las inducciones, las abducciones, las ponderaciones, etcétera.

Así, considero que no es posible eliminar una herramienta tan poderosa como la lógica en el diseño metodológico y en la construcción de argumentos, pero es importante precisar que los razonamientos que expresamos en las sentencias no pueden reducirse solamente a la silogística aristotélica o lógica clásica que algunos llaman "lógica tradicional".

A decir de Manuel ATIENZA, la justificación, la motivación de las decisiones va más allá de la lógica formal. Este autor hace referencia a algunos teóricos contemporáneos de la argumentación jurídica que apoyan esta afirmación: Neil MACCORMICK sostiene que la justificación judicial de tipo deductivo (es decir, logico-formal) es suficiente en los casos fáciles pero no en los difíciles; Robert ALEXY considera que la argumentación jurídica es un caso especial de la argumentación práctica general, y que se caracteriza porque en ella rigen las reglas de discurso práctico general (que no son sólo reglas lógicas, sino también reglas de carácter semántico y pragmático) y reglas específicas del discurso jurídico, dentro de las cuales existen reglas referidas a la justificación interna (lógico-deductivas) y las de la justificación externa (que no tienen naturaleza lógica, aunque algunas de ellas las formule recurriendo a la notación lógica); 
finalmente, para Carlos NiNO, el razonamiento jurídico no es un razonamiento autónomo sino que depende, entre otros factores, de la moral, lo cual implica que no puede ser entendido en términos puramente formales ${ }^{11}$.

El autor considera, por otro lado, que otra de las limitaciones de la lógica formal (la llamada "tradicional") se refiere a que sus esquemas no son a veces adecuados para dar cuenta de los argumentos, o de cierto tipo de argumentos. Es necesario recurrir a instrumentos que no son sólo los de la lógica formal ordinaria: la lógica deóntica (o lógica de las normas); lógicas divergentes tales como las lógicas no monótonas, borrosas o paraconsistentes; esquemas de tipo inductivo o abductivo; o análisis de la estructura de los esquemas de los argumentos que se mueven en un plano menos abstracto que los de la lógica formal ${ }^{12}$. Conviene detenernos un poco en la definición de este tipo de lógicas, a manera de estricta orientación:

a) Lógica deóntica. En 1951 G. H. VON WRIGHT escribió un artículo titulado «Deontic Logic» ${ }^{13}$, con el que se considera como el fundador de lógica deóntica, que no es otra cosa que la aplicación de la lógica (que tradicionalmente se había aplicado sólo a proposiciones, esto es, a enunciados verdaderos o falsos) a las normas. Esencialmente, viene a establecer en este artículo las relaciones lógicas entre normas lo encontramos en el famoso cuadro de oposiciones deónticas o cuadro de Apuleyo ${ }^{14}$ :

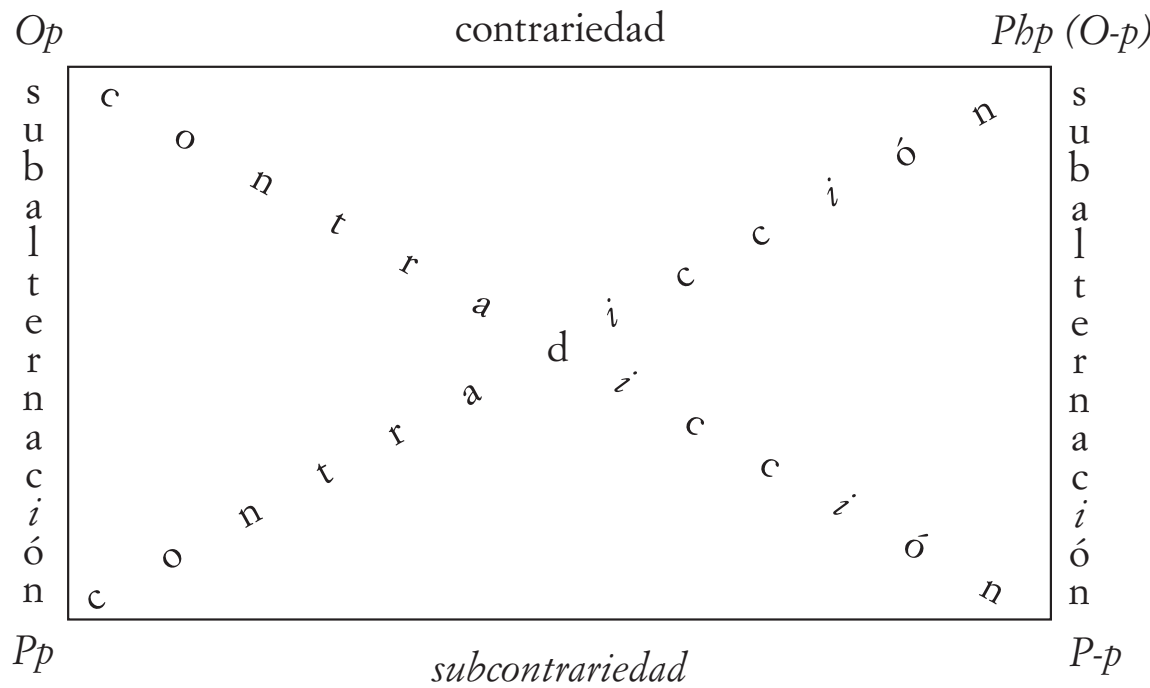

11 AtienZa, M., 2006: El Derecho como argumentación, Barcelona: Ariel, pp. 176 y 177.

12 ATIENZA, 2006.

13 Von Wright, G. H., 1957: «Deontic Logic», en Logical Studies, Londres: Routledge and Kegan Paul, pp. 58-74 (primera publicación: Mind, vol. 60, 1951, pp. 1-15). Véase también: AlCHOURRÓN, C. E., y BulYGIN, E., 1975: Introducción a la metodología de las ciencias jurídicas y sociales, Buenos Aires: Astrea.

14 Sobre el origen y el análisis de este cuadro véase GARRIDO, M., 1981: Lógica simbólica, Madrid: Tecnos, pp. 154 y s.; VERNAUX, R., 1972: Introducción general y Lógica, versión castellana de POMBO, J. A., Barcelona: Herder, pp. 113-116. 
De la lectura de este cuadro se pueden extraer los siguientes principios: el principio de subcontrariedad nos dice que, dada una acción determinada (p), o bien está permitido cumplirla $(\mathrm{Pp})$, o bien está permitido omitirla (P-p). Podemos formalizar a este principio como $\mathrm{Pp} \mathrm{v}$ P-p. El principio de contrariedad afirma que un mismo acto no puede ser a la vez obligatorio y prohibido: -(Op \& Php). De acuerdo con los principios de subalternación, si algo es obligatorio, entonces está también permitido (Op $\rightarrow \mathrm{Pp}$ ) y si algo está prohibido, entonces su omisión está permitida (Php $\rightarrow$ P-p). De acuerdo con los principios de contradicción no puede ser que una acción sea obligatoria y al mismo tiempo esté permitida su omisión, ni puede ser que la misma acción esté al mismo tiempo prohibida y permitida: -(Op \& P-p); -(Php \& Pp). La diferencia entre contrariedad y contradictoriedad es la siguiente: dos proposiciones contrarias no pueden ser ambas verdaderas, pero sí ambas falsas, mientras que dos proposiciones contradictorias no pueden ser ni ambas verdaderas ni ambas falsas.

b) Lógicas no monótonas. Este tipo de lógicas se basan en la aplicación de reglas dependientes básicamente del contexto y pretenden servir no en relación con el producto, sino con el proceso de la argumentación. Esencialmente establecen restricciones con respecto al uso de las reglas de inferencia clásicas, esto es, rompen con la monotonía de la lógica formal que, como se sabe, parte del carácter no excluyente de los nuevos axiomas añadidos a los ya existentes. Las lógicas no monótonas tienen en cuenta la necesidad de detectar posibles inconsistencias con los nuevos axiomas. ATIENZA y otros autores señalan que el razonamiento jurídico tiene un carácter esencialmente no monotónico ${ }^{15}$.

c) Lógicas borrosas o de lo difuso. Estas lógicas parten de la llamada "teoría de los conjuntos borrosos" ideada para dar cuenta de las nociones borrosas o vagas. Las lógicas borrosas no son bivalentes como lo es la lógica formal tradicional en la que sólo existen dos valores de verdad: falso y verdadero; son más bien lógicas polivalentes o plurivalentes, porque admiten diversos grados de verdad y de falsedad. Gracias a esa propiedad, permiten manejar informaciones borrosas ${ }^{16}$. En el Derecho (y sobre todo en el Derecho constitucional) se manejan cuestiones borrosas que no pueden ser resueltas con modelos de lógica formal o bivalente. Cuando se trata, por ejemplo, de determinar si un poder ha invadido la esfera competencial de otro esta Suprema Corte de Justicia de la Nación ha señalado que pueden existir diversos grados como la no intromisión, la no dependencia y la no subordinación. La naturaleza de ese problema era borrosa o difusa y la solución que ahí se presentó no respondía en modo alguno a la lógica tradicional ${ }^{17}$.

15 Véase AtienZa, 206: pp. 119 y 133-135.

16 AtienZA, 2006:, pp. 135-137. Véase también MazZARESE, T., 1996: «Lógica borrosa y decisiones judiciales: el peligro de una falacia racionalista», en Doxa Cuadernos de Filosofía del Derecho, n. ${ }^{\circ}$ 19, Alicante: Departamento de Filosofía del Derecho de la Universidad de Alicante, pp. 201-228.

${ }_{17}$ Tesis P./J. 80/2004 de la Novena Época, emitida por el Pleno de esta Suprema Corte de Justicia de la Nación, consultable en la p. 1122 del tomo XX, correspondiente a septiembre de 2004 del Semanario Judicial de la Federación y su Gaceta, que a la letra dice (se añaden énfasis): «DIVISIÓN DE PODERES. PARA EVITAR LA VULNERACIÓN A ESTE PRINCIPIO EXISTEN PROHIBICIONES IMPLÍCITAS REFERIDAS A LA NO INTROMISIÓN, A LA NO DEPENDENCIA Y A LA NO SUBORDINACIÓN ENTRE LOS PODERES PÚBLICOS DE LAS ENTIDADES FEDERATIVAS. El art. 116 de la Constitución Política de los Estados Unidos Mexicanos prescribe implícitamente tres mandatos prohibitivos dirigidos a los poderes públicos de las entidades federativas, para que respeten el principio de división de poderes, a saber: a) a 
d) Lógicas paraconsistentes. Estas lógicas pretenden construir sistemas que permitan manejar informaciones o proposiciones contradictorias. A decir de ATIENZA, es ellas rige el «principio de Duns Scoto» según el cual de una contradicción se sigue cualquier cosa. Si se aplicara al sistema jurídico, cualquier contradicción entre normas permitiría inferir cualquier otra norma o proposición normativa. En esas lógicas se construyen cálculos lógicos que no aceptan el principio referido, sino que más bien permitan efectuar deducciones con enunciados contradictorios, sin que se derive cualquier proposición ${ }^{18}$.

e) Esquemas inductivos. Se trata de esquemas argumentativos en los que no puede demostrarse la verdad de sus conclusiones como consecuencias necesarias de sus premisas, sino que sólo pretenden apoyarlas como probablemente verdaderas ${ }^{19}$. Este tipo de argumentos se llaman de manera genérica inductivos, aunque es más correcto llamarlos no deductivos. Entre ellos se encuentra la analogía.

f) Abducción o retroducción. Se trata de un razonamiento a partir del cual se trata de inferir un hecho particular a partir de otro hecho que se conoce y de una regla (universal o probabilística) que se supone correcta. La conclusión que se obtiene no es necesariamente verdadera, sino que sólo se trata de una convicción que puede ser más o menos razonable ${ }^{20}$.

Pablo Raúl BONORINO ha señalado que, a partir de las diversas definiciones que de este tipo de esquemas hace Charles SANDERS PIERCE — considerado uno de los autores más influyentes en el tema de la abducción-, se pueden tener como características definitorias de la abducción las siguientes: «i) es el proceso de formar una hipótesis explicativa; ii) es la única operación lógica que introduce un nuevo conocimiento; iii) parte de los hechos con la sensación de que los mismos pueden explicarse mediante una teoría; iv) consiste en la búsqueda de esa teoría, la que es sugerida por la consideración de los hechos» ${ }^{21}$.

$* * *$

\footnotetext{
la no intromisión, b) a la no dependencia y c) a la no subordinación de cualquiera de los poderes con respecto a los otros. La intromisión es el grado más leve de violación al principio de división de poderes, pues se actualiza cuando uno de los poderes se inmiscuye o interfiere en una cuestión propia de otro, sin que de ello resulte una afectación determinante en la toma de decisiones o que genere sumisión. La dependencia conforma el siguiente nivel de violación al citado principio, y representa un grado mayor de vulneración, puesto que implica que un poder impida a otro, de forma antijurídica, que tome decisiones o actúe de manera autónoma. La subordinación se traduce en el más grave nivel de violación al principio de división de poderes, ya que no sólo implica que un poder no pueda tomar autónomamente sus decisiones, sino que además debe someterse a la voluntad del poder subordinante; la diferencia con la dependencia es que mientras en ésta el poder dependiente puede optar por evitar la imposición por parte de otro poder, en la subordinación el poder subordinante no permite al subordinado un curso de acción distinto al que le prescribe. En ese sentido, estos conceptos son grados de la misma violación, por lo que la más grave lleva implícita la anterior». Controversia constitucional 35/2000. Poder Judicial del Estado de Aguascalientes. 22 de junio de 2004. Unanimidad de nueve votos. Ausente: Mariano Azuela Güitrón. Ponente: José Ramón Cossío Díaz. Secretarios: Pedro Alberto Nava Malagón y Roberto Lara Chagoyán.

${ }^{18}$ Véase ATIENZA, 2006: pp. 137 y ss.

${ }_{19}$ Cfr. Copi; Irving, M., y CoHen, C., 2001: Introducción a la Lógica, México: Limusa, 2001, pp. 443 y 444 .

${ }^{20}$ Cfr. GonzÁlez Lagier, D., 2005: Quaestio Facti. Ensayos sobre prueba, causalidad y acción, LimaBogotá: Palestra-Temis, p. 70.

${ }^{21}$ Bonorino, P. R., 1993: «Sobre la abducción», en Doxa Cuadernos de Filosofía del Derecho, n. ${ }^{\circ}$ 14, Alicante: Departamento de Filosofía del Derecho de la Universidad de Alicante, p. 218. En este artículo puede
} 
Sin desconocer, pues, que existen estas lógicas modernas o no clásicas, no dejamos de reconocer, como hace la teoría contemporánea de la argumentación jurídica, que la lógica clásica sigue teniendo un papel fundamental en los esquemas argumentativos del Derecho. Lo que me perece importante subrayar es que la lógica tradicional no juega ya ese papel estrictamente silogístico del modelo aristotélico. Respecto al papel que juega actualmente la lógica formal en matera jurídica, recojo algunas ideas de Manuel ATIENZA.

Este autor considera que los análisis lógico-formales y los relativos a otros tipos de esquemas de razonamiento no son incompatibles. ATIENZA ve a la lógica informal como complemento de la lógica formal y no como una alternativa a ésta. Para él, la lógica formal es el núcleo de la concepción o de la perspectiva formal de la argumentación, pero ella es sólo una de las perspectivas desde las que pueden considerarse los argumentos; existen también la concepción material y la pragmática ${ }^{22}$.

Existen, puede decirse, dos grandes universos: el de los defensores a ultranza de la lógica (llamados por ATIENZA imperialistas de la lógica) y el de los partidarios del antilogicismo. Los primeros sostienen que la argumentación jurídica es exclusivamente de carácter deductivo formal. En palabras del autor, «...se trataría del formalismo jurídico que reduce toda la argumentación jurídica al silogismo judicial de carácter subsuntivo» ${ }^{23}$. Los representantes de las tesis antilogicistas afirman que la lógica formal no ocupa ningún lugar en el razonamiento jurídico. ATIENZA considera que contra lo que hay que estar no es contra la lógica, sino contra sus pretensiones imperialistas.

Para este autor, las contribuciones más importantes de la lógica a la argumentación jurídica consisten en lo siguiente:

«1. Ofrecer esquemas, formas de argumentación, que ayudan a ordenar los argumentos y a dar, cuando menos, una primera idea de su posible validez. Eso tiene importancia no sólo cuando se trata de analizar o evaluar un argumento, sino también cuando se tiene que construir un argumento. El conocimiento de la lógica da claridad a la argumentación.

2. Suministrar una ayuda importante para la interpretación y la conceptualización. La lógica proporciona un lenguaje - formal - al que traducir los argumentos del lenguaje natural y permite, por ello, darse cuenta de que un mismo argumento (o fragmento lingǘstico) expresado en un lenguaje natural puede ser formalizado (interpretado) de diversas maneras. Obviamente, la lógica no resuelve el problema de interpretación, pero ayuda a ver dónde está el problema. Por ello también (porque ayuda a detectar imprecisiones - $\mathrm{y}$ a evitarlas-) es un poderoso instrumento para la redacción de textos jurídicos: jla forma tiene mucho que ver con el contenido!

Y por lo que hace a la conceptualización, dado que un concepto viene a ser el significado, el contenido, de una proposición, comprender un concepto viene a equivaler a ser capaz de mostrar — y hacer explícito- lo que se sigue y lo que no se sigue de esa proposición; un concepto es algo así como un "nudo" de una red inferencial.

3. Proporcionar un criterio para el control de los argumentos. La lógica —al menos, la lógica deductiva clásica - no se ocupa de la actividad, del proceso, de la argumentación, sino del resultado, del producto; pero eso no la priva de interés. La lógica no refleja cómo

encontrarse un interesante estudio sobre el tema de la abducción aplicada al Derecho. Véase también: ScHum, D. A.: «Species of Abductive Reasoning in Fact Investigation in Law», en Cardozo Law Review, n. 22.

${ }^{22}$ Véase ATIEnZA, 2006: pp. 176 y 177.

${ }^{23}$ AtienZA, 2006: p. 178. 
de hecho argumentamos, pero nos da moldes con los que reconstruir esa argumentación, una vez que ha tenido lugar (y moldes que nuestros argumentos pueden seguir). Desde el punto de vista de la lógica deductiva, la mayor parte de los argumentos que efectuamos en la vida cotidiana (y en el Derecho) son entimemáticos, esto es, no explicitan todas sus premisas. La lógica deductiva es un método para hallar las premisas que faltan y, en consecuencia, para controlar la calidad de los argumentos, pues nos lleva a plantearnos la cuestión de hasta qué punto esas premisas implícitas son o no aceptables» ${ }^{24}$.

\section{SOBRE LOS REQUISITOS QUE DEBEN CUMPLIR LOS CRITERIOS IMPLÍCITOS}

Considero que este tipo de contradicciones de tesis — las que contienen al menos un criterio implícito- deben cumplir con los siguientes requisitos:

3.1. Cumplir con las exigencias formales del entimema. Entre las diversas maneras que existen para definir al entimema, emplearé aquí la más conocida, esto es, la que suele utilizarse por los lógicos ${ }^{25}$. Un entimema es un razonamiento correcto pero que no muestra alguna premisa. Ésta (la premisa omitida) fácilmente se puede deducir del razonamiento mismo. Por ello se dice que en los entimemas las premisas existen, pero no se mencionan expresamente.

Según Irving M. Copi y Carl CoHEN, el uso de expresiones entimemáticas tanto en el discurso cotidiano como en la ciencia se debe a que una gran cantidad de proposiciones se pueden presumir del conocimiento común y, gracias a su uso, se evitan problemas, dado que no es necesario repetir lugares comunes y frases hechas que los oyentes o lectores pueden perfectamente aportar. Incluso, los autores hablan de una conveniencia retórica en su uso: «...no es raro que un argumento sea retóricamente más poderoso y persuasivo cuando se enuncia entimemáticamente que cuando se enuncia con su detalle. Como escribió ARISTÓTELES en su Retórica, "los discursos que... descansan en entimemas despiertan los más entusiastas aplausos" ${ }^{26}$.

De acuerdo con la parte del silogismo que se deja sin expresar, existen varios tipos de entimemas: un entimema de primer orden es aquel en el que no se enuncia la premisa mayor del silogismo:

1) Pedro nació en México.

2) Por lo tanto, Pedro es un ciudadano mexicano.

24 ATIENZA, 2006: pp. 179 y 180.

25 Como señala FerRATer Mora, el término entimema se ha empleado desde Aristóteles con diversos significados; William HAMILTON — dice- distingue entre diecisiete acepciones del término. Conviene hacer alguna referencia de algunas de las acepciones más comunes. 1) Según ARISTÓTELES, el entimema es un silogismo basado en semejanzas o signos que pueden ser entendidos de tres modos de acuerdo con la posición del término medio en las figuras. 2) Por otro lado, el entimema expresa — también según ARISTÓTELES— la demostración de un orador y constituye la más efectiva de las maneras de demostración; es decir, el entimema es una clase de silogismo: el silogismo retórico. 3) Para algunos autores las dos definiciones de ARISTÓTELES coinciden, por lo que lo importante en el entimema es el que sea un razonamiento cuyas premisas son meramente probables o constituyen simplemente ejemplos. 4) Por otro lado, en términos lógicos, un entimema es un silogismo formulado en forma incompleta, por no ser expresada una de las premisas o la colnclusión. Cfr. Ferrater Mora, 1997: Diccionario de Filosofía, Madrid: Alianza Editorial, pp. 242 y 243.

${ }^{26}$ Cfr. Copi y CoHen, 2001: p. 294. 
La premisa omitida es la mayor en el silogismo anterior: Todos los nacidos en México son ciudadanos mexicanos.

Un entimema de segundo orden es aquel en el que se suprime la premisa menor:

1) Todos los Ministros de la Suprema Corte de Justicia de la Nación son licenciados en Derecho.

2) Por lo tanto, el Presidente de la Segunda Sala es licenciado en Derecho.

La premisa omitida - pero existente- en el anterior razonamiento es: El Presidente de la Segunda Sala es Ministro de la Suprema Corte de Justicia de la Nación.

Un entimema de tercer orden es uno en el cual se enuncian ambas premisas pero se suprime la conclusión. Un ejemplo de este tipo es el siguiente:

1) Ningún verdadero cristiano es vano, pero 2) algunos clérigos son vanos.

La conclusión omitida sería: 3) Por lo tanto, algunos clérigos no son verdaderos cristianos $^{27}$.

En todos estos casos, el hecho de que no se mencione la proposición omitida (como premisa mayor, menor o conclusión) no implica que ésta no exista, pues fácil y necesariamente se puede deducir de la relación entre la premisa mayor y la conclusión.

Hasta aquí todo parece claro; sin embargo, es sumamente importante vigilar que en el proceso de construcción del entimema no se cometan errores formales que provoquen la invalidez del argumento.

En el caso de las contradicciones de tesis basadas en criterios implícitos es necesario que éste no contenga un razonamiento deficiente en el que no resulte obvio cuál sea la premisa omitida o no expresada, es decir, es importante vigilar que no se trate de entimemas inválidos. Ejemplo:

1) Todos los tlaxcaltecas son mexicanos.

2) Por lo tanto, Pedro es tlaxcalteca.

La premisa omitida sería: Pedro es mexicano.

Debido a que aquí se comete la falacia de la afirmación del consecuente, no se sabe si Pedro es o no tlaxcalteca, pues puede ser mexicano pero no necesariamente tlaxcalteca.

Retomando el ejemplo referido a los entimemas de tercer orden, citado líneas arriba, podemos demostrar, con un error en la conclusión, que el argumento puede ser inválido:

1) Ningún verdadero cristiano es vano, pero 2) algunos clérigos son vanos.

$\mathrm{Si}$ alguien concluye que «algunos cristianos verdaderos no son clérigos», entonces este entimema es inválido, pues comete la falacia de proceso ilícito del término mayor.

Es, pues, importante distinguir entre entimema válido e inválido. Según Irving M. COPI y Carl COHEN, un argumento que se enuncia (de manera incompleta) de tal forma

${ }^{27}$ El ejemplo es de Copi y CoHEn, 2001: p. 295. 
que una parte de él se da por entendida se llama entimema ${ }^{28}$. No se trata de un razonamiento incompleto en sí mismo; lo incompleto se predica solamente de una parte de su expresión o enunciación. En cambio, existen razonamientos que son propiamente incompletos, esto es, no sólo su expresión es incompleta sino que realmente les falta un tramo en su construcción. Este tipo de argumentos, genuinamente incompletos, suelen presentarse falazmente como si fueran entimemas. Para poder identificar cuándo se está ante un entimema válido y cuándo ante un argumento inválido con apariencia de entimema, los autores mencionados hablan de dos pasos:

I. Primer paso. Consiste en proporcionar las partes faltantes del argumento. Para ello, es necesario, en primer lugar, identificar de qué orden es el entimema y, en segundo, expresar la proposición faltante, ya sea la premisa mayor, la menor o la conclusión.

Si no se cumple con este requisito se puede llegar a construir un falso entimema. Se puede dar por supuesta una proposición que en realidad no es la que realmente se omitió en la formulación del argumento y así cometer un error. Por ello, cuando el operador jurídico se encuentra ante un criterio implícito, es sumamente importante que entienda qué parte del argumento está siendo omitida, es decir, si se trata de un entimema de primer, segundo o tercer orden y, por otro lado, resulta altamente conveniente que ensaye la proposición faltante para tener de manera completa - ya no entimemática - el argumento y pasar a comprobar su validez.

II. Segundo paso. Consiste en probar el silogismo resultante. Para ello es importante comprobar que en su construcción no se cometan falacias formales, esto es, que se cumplan las reglas del silogismo. Para ello, basta con que se observen las siguientes reglas:

a) Todo silogismo tiene que tener tres términos, ni más ni menos: el término mayor, el término menor y el término medio. Cada término debe tener el mismo significado y la misma suposición en sus dos usos. Si no se utilizan los términos de esta manera, se comete la falacia de los cuatro términos. Con esta regla queda prohibido el empleo de palabras equívocas.

b) Cualquier término que está distribuido en la conclusión tiene que estar distribuido en las premisas. Las premisas son la causa de la conclusión. Como cualquier efecto, la conclusión no puede contener más de lo que contiene la causa, ya que ningún efecto es mayor que su causa. Si un término fuera distribuido (o sea, utilizado universalmente) en la conclusión pero indistribuido (o sea, utilizado particularmente) en la premisa, entonces el efecto sería mayor que su causa, lo cual es imposible. La falacia que podría cometerse si no se respeta esta regla estriba en tener más en la conclusión que en las premisas.

c) El término medio debe estar distribuido al menos una vez. No se puede establecer una relación entre el término mayor y el término menor en la conclusión a menos que el término medio esté distribuido por lo menos una vez. Si no se puede establecer una identificación del término medio con cada uno de los otros términos, no seguiría ninguna conclusión.

${ }^{28}$ Copi y CoHen, 2001: pp. 295-299. 
d) De dos premisas negativas, nada se sigue. Si ambas premisas son negativas, ambas niegan una identidad entre sus términos y el término medio. No podemos averiguar si el término mayor y el menor están relacionados de alguna manera o no. Podría pensarse que de dos premisas negativas podría seguirse una conclusión negativa, pero no se puede probar nada. Para llegar a una conclusión negativa, cuya verdad es demostrado por las premisas, hay que utilizar una premisa afirmativa.

e) La conclusión siempre sigue la parte más débil. Esta regla indica que la conclusión no puede ser más fuerte que las premisas. Así, cualquier debilidad en las premisas tiene que reflejarse en la conclusión, que sigue como efecto de las premisas. Lo "débil" de una proposición se predica de su aspecto cuantitativo y de su aspecto cualitativo. En el primer caso, una proposición particular es más débil que una universal porque pretende decir menos; mientras que, en el segundo caso, una proposición negativa es más débil que una proposición afirmativa, porque lo único que predica es el no ser.

Hasta aquí las reglas. Tomar en cuenta lo anterior, no es un problema menor. Los argumentos entimemáticos suelen ser criticados porque, por su estructura, se presentan como vulnerables ante la detección de falacias.

COPI y COHEN señalan que la objeción más demoledora en contra de los entimemas consiste en mostrar que ninguna premisa, no importa cuán inverosímil sea, puede convertir el entimema en un silogismo categórico válido ${ }^{29}$.

Como se vio, para determinar si un entimema es o no válido no se requiere nada más que las reglas de la lógica formal. No hay, pues, una «lógica de los entimemas». Dicen los autores citados que la validez lógica de los entimemas se pone a prueba con los mismos métodos que se aplican a los silogismos categóricos que de forma estándar y que la diferencia entre entimemas y silogismos es retórica más que lógica ${ }^{30}$.

3.2. El segundo requisito para determinar si un criterio es implícito o no es vigilar que se trate de una sola línea argumentativa, ya que a partir de ciertas premisas dadas se pueden construir varios razonamientos entimemáticos. El operador jurídico ha de tener bien claro a qué argumento se está refiriendo con el entimema. Veamos ejemplos de razonamiento completo, de ese mismo razonamiento convertido en un entimema y de un entimema ajeno al argumento inicial:

Argumento completo:

1) Todos los mamíferos son animales.

2) El gato es mamífero.

3) Por lo tanto, el gato es animal.

El entimema sería:

1) Todos los mamíferos son animales.

2) Por lo tanto, el gato es animal.

El entimema que se construye a partir de un elemento del razonamiento inicial, pero que se aparta de la línea argumentativa, sería el siguiente:

\footnotetext{
29 Copi y CoHen, 2001: p. 296.

30 Copi y CoHen, 2001.
} 
Como todos los mamíferos son animales, entonces los mamíferos son seres vivos.

Es decir, el operador jurídico, a partir del criterio que se presenta como implícito, debe buscar cuál fue la proposición omitida y reconstruir el argumento como se señaló en el apartado anterior, pero sin perder de vista el argumento central.

\section{ASPECTOS FORMALES Y MATERIALES EN LAS CONTRADICCIONES DE TESIS}

Finalmente, me parece conveniente hacer algunos comentarios con respecto a la forma de proceder de la Suprema Corte de Justicia de la Nación al resolver contradicciones de tesis.

Por lo general, este tipo de asuntos se resuelven a partir de criterios como el siguiente:

«Contradicción de tesis de tribunales colegiados de circuito. Requisitos para su existencia. De conformidad con lo que establecen los arts. 107, fracción XIII, primer párrafo de la Constitución Federal y 197-A de la Ley de Amparo, cuando los Tribunales Colegiados de circuito sustenten tesis contradictorias en los juicios de amparo de su competencia, el Pleno de la Suprema Corte de Justicia o de la Sala que corresponda deben decidir cuál tesis ha de prevalecer. Ahora bien, se entiende que existen tesis contradictorias cuando concurren los siguientes supuestos: a) Que al resolver los negocios jurídicos se examinen cuestiones jurídicas esencialmente iguales y se adopten posiciones o criterios jurídicos discrepantes. b) Que la diferencia de criterios se presente en las consideraciones, razonamientos o interpretaciones jurídicas de las sentencias respectivas. c) Que los distintos criterios provengan del examen de los mismos elementos» ${ }^{31}$.

Los requisitos mencionados en el criterio señalado, a mi juicio, no aclaran suficientemente los pasos que se tienen que dar para comprobar si una contradicción existe o no. Como puede verse, el inciso a) no se diferencia esencialmente del inciso $c$ ), pues «que se examinen cuestiones jurídicas esencialmente iguales» es equivalente a «que los distintos criterios provengan del examen de los mismos elementos». Así las cosas, la tesis se reduce en realidad a dos condiciones:

1) Que al resolver los negocios jurídicos se examinen cuestiones jurídicas esencialmente iguales y se adopten posiciones o criterios jurídicos discrepantes.

2) Que la diferencia de criterios se presente en las consideraciones, razonamientos o interpretaciones jurídicas de las sentencias respectivas.

Considero que estos requisitos pasan por alto el aspecto lógico (aquí sí, lógico formal) inherente a toda contradicción, no sólo de criterios jurídicos sino en general de cualquier tipo de afirmación. No sostengo, sin embargo, que el aspecto lógico tenga que ser visto como una condición necesaria y suficiente, pues ciertamente el empleo de la lógica formal como único método para resolver problemas jurídicos es una cuestión superada. Pero lo que sí considero es que, como resolutores de contradicciones

31 Tesis 4a./J. 22/92, de la Octava Época, emitida por le Cuarta Sala de la Suprema Corte de Justicia de la Nación, consultable en la p. 22, del t. 58, correspondiente a octubre de 1992, de la Gaceta del Semanario Judicial de la Federación. 
de tesis, los ministros de la Suprema Corte de Justicia de la Nación no podemos descuidar ese aspecto formal.

Así, el primer paso que, a mi juicio, debe darse a la hora de resolver una contradicción de tesis es comprobar que el tipo de oposición lógica existente entre los criterios permita comprobar que lo que uno de ellos afirma acerca de un mismo problema, el otro lo niegue, ya que, según el principio lógico de contradicción, dos enunciados referidos al mismo problema, y que sean contradictorios entre sí, no pueden afirmar y negar el mismo contenido. Debe tratarse, pues, de criterios excluyentes.

Una vez agotado el aspecto formal, es necesario verificar que las posiciones opuestas se susciten en un mismo plano de análisis, es decir, comprobar que cuando se hayan resuelto cada uno de los asuntos, se hayan examinado cuestiones jurídicas esencialmente iguales, y que se hayan adoptado criterios discrepantes. Lo anterior significa que no basta atender a la conclusión de los razonamientos, sino que es necesario tener en cuenta las circunstancias fácticas y jurídicas que llevaron a los respectivos tribunales a asumir su criterio.

Asimismo, al estudiar las circunstancias aludidas se debe distinguir entre las que sirven de fundamento de los criterios emitidos y aquellas que sólo aparentemente lo sean.

En suma, se actualiza la contradicción de tesis cuando concurren las siguientes condiciones:

a) Los criterios deben ser, en términos lógicos, efectivamente contradictorios, es decir, que sea posible comprobar que lo que uno de ellos afirme acerca de un mismo problema, el otro lo niegue.

b) Las cuestiones jurídicas planteadas deben ser esencialmente iguales, es decir, deben provenir del examen de los mismos elementos, habiéndose adoptado criterios discrepantes.

c) La diferencia de criterios debe presentarse en las consideraciones, razonamientos o interpretaciones jurídicas de las sentencias respectivas.

Como puede verse, el primer requisito se refiere al aspecto lógico y los otros dos a los aspectos materiales de la contradicción. Uno y otros aspectos resultan indispensables para poder detectar adecuadamente una genuina contradicción, esto es, una oposición lógica en la que los enunciados que se confrontan contienen juicios excluyentes entre sí.

Considero que utilizando este método podría ahorrarse una gran cantidad de trabajo, dado que ante la Suprema Corte de Justicia de la Nación se somete una gran cantidad de casos de contradicción que en realidad no lo son.

Termino con el planteamiento de un problema adicional: ¿qué se entiende por "cuestión jurídica"? Lo primero es señalar que se trata de un concepto vago. Por el mismo puede entenderse, por lo menos: 1) la interpretación de un precepto normativo en sentido abstracto (norma en relación con una clase de hechos); 2) la interpretación de un precepto normativo en sentido concreto (norma con relación a un hecho concreto); 3) la interpretación — concreta o abstracta - de cuestiones que no tienen la entidad de normas jurídicas pero que pertenecen al sistema, tales como las definiciones legales, los nombramientos, las declaraciones legales o la jurisprudencia; 4) un 
hecho cualquiera que se presenta como problema ante la instancia jurisdiccional para ser resuelto "desde el Derecho"; y finalmente, 5) el esclarecimiento de un concepto indeterminado o esencialmente controvertido, con independencia de que se encuentre en una disposición, definición o hecho.

Considero que en cada contradicción de tesis debe determinarse de qué tipo de cuestión jurídica se trata, pues puede tratarse de más de uno de los supuestos señalados, con excepción de la primera, pues ese tipo de análisis corresponden más al campo del control abstracto de la constitución (acciones de inconstitucionalidad), la dogmática jurídica o a la política legislativa, y no a la contradicción de tesis. 